\title{
Significance of a Tumor Microenvironment- Mediated P65-miR-30a-5p-BCL2L11 Amplification Loop in Multiple Myeloma
}

\section{Ling Xie ( $\sim$ xll19882021@163.com )}

Affiliated Hospital of Nantong University https://orcid.org/0000-0002-0704-3551

\section{Xiuying Shi}

Nantong University Affiliated Hospital: Affiliated Hospital of Nantong University

Hongming Huang

Nantong University Affiliated Hospital: Affiliated Hospital of Nantong University

Shaoqing Ju

Nantong University Affiliated Hospital: Affiliated Hospital of Nantong University

\section{Xudong Wang}

Nantong University Affiliated Hospital: Affiliated Hospital of Nantong University

\section{Research Article}

Keywords: myeloma cells, cell adhesion-mediated drug resistance, bone marrow stromal cells, NF-KB signaling pathway

Posted Date: September 17th, 2021

DOl: https://doi.org/10.21203/rs.3.rs-880497/v1

License: (c) (i) This work is licensed under a Creative Commons Attribution 4.0 International License. Read Full License

Version of Record: A version of this preprint was published at Experimental Cell Research on March 1st, 2022. See the published version at https://doi.org/10.1016/j.yexcr.2022.113113. 


\section{Abstract}

Despite significant progress in the treatment of myeloma, multiple myeloma (MM) remains an incurable hematological malignancy due to cell adhesion-mediated drug resistance (CAM-DR) phenotype. However, data on the molecular mechanisms underlying the CAM-DR remains scanty. Here, we identified a miRNAmRNA regulatory network in myeloma cells that are directly adherent to bone marrow stromal cells (BMSCs). Our data showed that the BMSCs up-regulated miR-30a-5p and down-regulated BCL2L11 at both mRNA and protein level in the myeloma cells. Besides, luciferase reporter genes demonstrated direct interaction between miR-30a-5p and BCL2L11 gene. Moreover, the BMSCs activated NF-KB signaling pathway in myeloma cells and the NF-KB P65 was shown to directly bind the miR-30a-5p promoter region. Moreover, suppression of the miR-30a-5p or upregulation of the BCL2L11 promoted apoptosis of the myeloma cells independent of the BMSCs, thus suggesting clinical significance of miR-30a-5p inhibitor and PLBCL2L11 plasmid in CAM-DR. Together, our data demonstrated the role of P65-miR-30a5p-BCL2L11 loop in CAM-DR myeloma cells. These findings give new insights into the role of tumor microenvironment in the treatment of patients with myeloma.

\section{Introduction}

Multiple myeloma, characterized by uncontrolled proliferation of plasma cells in the bone marrow, is a progressive and incurable disease. Unlike solid tumors that could be treated using surgical means, chemotherapy remains the main treatment option for MM. Despite significant progress in the treatment of myeloma, MM remains an incurable hematological malignancy due to drug resistance. There is, therefore, need for studies on the molecular mechanisms of MM to circumvent the development of drug resistance. Accumulating evidence has shown that tumor micro-environment provides a survival sanctuary for the myeloma cells. As a cellular compartment of the tumor microenvironment, bone marrow stromal cells (BMSCs) have been demonstrated to activate various signaling pathways through direct adhesion with the myeloma cells and in the secretion of various cytokines and growth factors. These cascade of events leads to the survival, growth, proliferation, migration, and development of drug resistance in myeloma cells. To date, data on the molecular mechanisms underlying the interaction between the BMSCs and myeloma cells remain limited.

NF-KB is an important nuclear transcription factor that controls gene transcription in cells. It plays a key role in physiological and pathological processes such as cellular proliferation and apoptosis, developmental and inflammatory processes as well as immune responses. A recent study associated the NF-KB signaling pathway with chemoresistance in myeloma ${ }^{1}$. In addition, Jin et $\mathrm{al}^{2}$ showed that inhibition of the NF-KB signaling pathway suppressed the migration and invasion of myeloma cells and induced cellular apoptosis. Another study demonstrated that activation of the NF-kB signaling pathway induced bortezomib (proteasome inhibitor) resistance in myeloma cells ${ }^{3}$. Thus, the data suggested that the NF-KB signaling pathway mediates the progression of myeloma and chemotherapy resistance. However, whether the BMSCs regulate the NF-KB signaling pathway in the myeloma cells has yet to be elucidated. 
On the other hand, miRNA is highly conserved and regulates gene expression at the post-transcriptional level by inhibiting or degrading specific target mRNA. Numerous studies have shown that the miRNAs play critical regulatory roles in MM drug resistance, including CAM-DR ${ }^{4-7}$. For instance, BMSCs modulate multiple miRNAs in MM cells, and over-expressed miR-101-3p was shown to trigger apoptosis of myeloma cells and partially circumvented BMSCs-induced bortezomib resistance ${ }^{8}$. Hao et al showed that BMSCs enhanced the survival of myeloma cells and protected them from bortezomib induced apoptosis via suppression of miRNA-15a ${ }^{9}$. Furthermore, CAM-DR was partially abolished by ectopic inhibition of miR-182 expression in myeloma cells ${ }^{4}$. Similarly, data has shown that BMSCs upregulated miR-21 while miR-21 inhibition increased the susceptibility of myeloma cells to chemotherapy ${ }^{10}$. Therefore, BMSCs could be providing a survival advantage for myeloma cells by influencing the expression of miRNAs. However, the exact involvement of the miRNAs in the complex interaction between MM cells and BMSCs is yet to be defined.

BCL2L11 is a pro-apoptotic protein that regulates various cellular activities. Chen et al ${ }^{11}$ showed that BCL2L11 mediates bortezomib resistance in myeloma cells and upregulation of BCL2L11 reduces bortezomib resistance. Another study demonstrated that over-expression of BCL2L11 reversed multidrug resistance in myeloma cells ${ }^{12}$. Besides, it was shown that BCL2L11 is downregulated in drug-resistant myeloma cells, indicating that overexpression of BCL2L11 could increase the sensitivity of myeloma cells to therapy ${ }^{13}$. The role of BCL2L11 in myeloma cells that are adherent to the BMSCs is yet to be fully understood.

Here, we investigated the molecular mechanism of MM-BMSCs communication. We identified various miRNAs involved in the CAM-DR and elucidated the role of P65-miR-30a-5p-BCL2L11 loop in CAM-DR. Our findings highlight potential and new treatment strategies for patients with myeloma using the factors in the tumor micro-environment.

\section{Materials And Methods}

\section{Cell culture}

Human myeloma cell lines U266, RPMI 8226 and H929 were obtained from our lab. Primary human BMSCs were separated as previously described ${ }^{9}$ while myeloma CD138+ plasma cells were purified from bone marrow aspirates using CD138-based immunomagnetic selection (AutoMacs; Miltenyi) following the manufacturer's instructions. The purity of the CD138+ plasma cells was $>90 \%$. The cells were grown in DMEM basal medium (GIBCOBRL, Grand Island, NY, USA) supplemented with $15 \%$ fetal bovine serum (FBS, GIBCO-BRL), $1 \%$ penicillin-streptomycin and $1 \%$ glutamine in a humidified atmosphere with $5 \% \mathrm{CO}_{2}$ at $37^{\circ} \mathrm{C}$.

\section{RNA isolation and reverse transcription}


Total RNA was isolated from the myeloma cells using Trizol reagent (Invitrogen, USA) following the manufacturer's instructions. We then quantified the total RNA concentration using a nucleic acid protein ultraviolet analyzer (NanoPhotometer ${ }^{\mathrm{TM}}$, IMPLEN, German). We then synthesized complementary DNA (cDNA) from the RNA using the RevertAid First Strand cDNA Synthesis Kit (ThermoFisher Scientific, Waltham, USA) following standard protocols $\varangle 42^{\circ} \mathrm{C}$ for $60 \mathrm{~min}, 70^{\circ} \mathrm{C}$ for $5 \mathrm{~min}$. The reaction contained $1500 \mathrm{ng}$ of the RNA samples, $9 \mu \mathrm{l}$ of RT master mix including $2 \mu \mathrm{l}$ of $10 \mathrm{mM}$ dNTP mix, $1 \mu \mathrm{l}$ of $200 \mathrm{u} / \mu \mathrm{l}$ reverse transcriptase, $4 \mu \mathrm{l}$ of $5 \times$ reaction buffer, $1 \mu \mathrm{l}$ of $20 \mathrm{u} / \mu \mathrm{l}$ RNase inhibitor and $1 \mu \mathrm{l}$ of $62.5 \mathrm{nM}$ stem loop reverse transcription primers as well as nuclease-free $\mathrm{H}_{2} \mathrm{O}$ to $20 \mu \mathrm{l}$.

\section{Affymetrix chip screening for miRNA}

The myeloma cells U266, RPMI 8226 or H929 were co-cultured with primary BMSCs for 24 hours and then we aspirated the suspended myeloma cells gently for chip screening. The experiment was carried out using Affymetrix miRNA 4.0 chip following the manufacturer's instructions. The arrays were scanned by the Affymetrix Scanner 3000 (Affymetrix) while Affymetrix GeneChip Command Console software (version4.0, Affymetrix) was used to analyze the array images to obtain raw data and then performed RMA normalization. Thereafter, data analysis was performed by Genespring software (version 12.5, Agilent Technologies).

\section{Real-time quantitative polymerase chain reaction (qRT-PCR)}

We performed qRT-PCR at $95^{\circ} \mathrm{C}$ for $10 \mathrm{~min}, 95^{\circ} \mathrm{C}$ for $15 \mathrm{~s}, 60^{\circ} \mathrm{C}$ for $31 \mathrm{~s}$ and $72^{\circ} \mathrm{C}$ for $31 \mathrm{~s}$ for 40 cycles. The reaction was conducted in three replicate wells for each sample and the average data were calculated using the $2^{-\triangle \Delta \mathrm{Ct}}$ method. U6 was used as an internal control. The $20 \mu \mathrm{l} \mathrm{PCR}$ reaction system included $10 \mu \mathrm{l}$ SYBR Green $\otimes$ Mix, $0.7 \mu$ l forward primer, $0.7 \mu$ l reverse primer, $3.0 \mu \mathrm{l}$ cDNA and $5.6 \mu \mathrm{l}$ nuclease-free water.

\section{Cell transfection}

miR-30a-5p-mimics and their negative control, miR-30a-5p-inhibitor and its negative control were synthesized by GenePharma Inc. (Shanghai, China). The BCL2L11 overexpression plasmid, shRNA and negative controls were constructed by Jikai Company (Shanghai, China). Plasmid transfection experiment was carried out with lipofectamine 2000 (Invitrogen, Carlsbad, CA) following the manufacturer's instructions.

\section{Luciferase reporter assay}

Wild type (WT) or mutant (Mut) BCL2L11 3'UTRs were cloned into the luciferase reporter vector pSI-

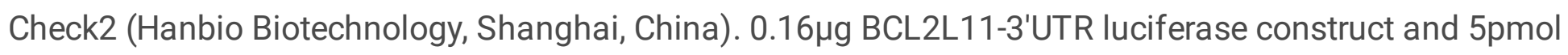
miR-30a-5p/negative control were transfected into HEK293T cells using lipofectamine 2000. The cells were harvested after $48 \mathrm{~h}$ of transfection and then the luciferase activity was measured by promega dualluciferase system following the manufacturer's instructions. 


\section{Western blot}

Anti-BCL2L11 (1:800, Cell Signal Technology, MA, USA), P65, phosphor-P65, phosphor-IKBa, histone (1:800, Santa Cruz Biotechnology, Santa Cruz, CA) and anti- $\beta$-actin antibodies (1:1000, Lianke Biotechnology Co., Ltd, Hangzhou, China) were used for the Western blot assays. Total protein, nucleoprotein and cytoplasm protein were extracted from the myeloma cells using the extract kit and cell lysis buffer (Beyotime Biotechnology Co., Ltd., Haimen, China). The protein purity and concentration were analyzed by a NanoPhotometer (Implen, Inc., CA, USA). After the PAGE, the proteins were transferred into PVDF membranes and then incubated with the primary antibodies. After blocking, the blots were incubated with secondary antibodies. Western blot bands were visualized in the gel imaging system machine using enhanced chemiluminescence (ECL) kit (Beyotime Biotechnology Co., Ltd., Haimen, China).

\section{NF-KB P65 nuclear translocation assay}

The NF-KB nuclear translocation assay was performed as previously described ${ }^{14}$. Briefly, the myeloma cells that were directly adherent to BMSCs were fixed, washed and then blocked with BSA for one hour at room temperature. The myeloma cells were subsequently incubated with anti-NF-kB p65 antibodies and Alexa Fluor488-conjugated secondary antibodies successively. On the other hand, the cell nucleus was stained with hoechst 33342. Images were evaluated by the leica dm500 fluorescence microscope (scale bar $₫ 50 \mu m$ ).

\section{Detection of apoptosis using flow cytometry}

We co-cultured the myeloma cells directly or indirectly with primary BMSCs, with or without bortezomib for 24 hours. The myeloma cells were transfected with miR-30a-5p mimics, inhibitor, BCL2L11 overexpression plasmid, BCL2L11 shRNA or negative controls. The myeloma cells were harvested and stained with annexin V-conjugated fluorescein isothiocyanate (FITC) and propidium iodide (PI) (BD Biosciences, Franklin Lakes, NJ, USA) following the manufacturer's instructions. Cell apoptosis was then detected by the FACScan flow cytometer (BD Biosciences).

\section{Chromatin immunoprecipitation (ChIP) assay}

Briefly, the myeloma cells were fixed and then crosslinking stopped with glycine, followed by isolation of the nuclei and cracking of the chromatin with a Branson Digital Sonifier D250 ultrasonic instrument. Afterwards, we incubated the diluted chromatin with anti-NF-KB p65 antibody at $4^{\circ} \mathrm{C}$ overnight and then eluted the chromatin from magnetic beads for quantitative PCR analysis. We used IgG as the negative control.

\section{Statistical analysis}

Statistical analysis was performed using SPSS Statistics 17.0 software (SPSS Inc., Chicago, IL, USA) and then related graphs were drawn by GraphPad Prism v 5.0 software (GraphPad Software Inc, La Jolla, CA, 
USA). Kolmogorov-Smirnov test was used to determine the normality of the distribution of the data in each group. Normally distributed variables were expressed as a mean \pm standard deviation (SD), while non-normally distributed variables were expressed as median $\left(25^{\text {th }}, 75^{\text {th }}\right.$ percentiles). The experiments were repeated three times. The statistical significance of the differences between related experimental groups was determined by one-way analysis of variance (ANOVA). A $p<0.05$ was considered as statistically significant.

\section{Results}

\section{BMSCs protect myeloma cells from bortezomib-induced apoptosis}

To evaluate the effect of primary BMSCs on the myeloma cells, we co-cultured the myeloma cells U266 and 8226 with primary BMSCs and incubated with or without $100 \mathrm{nmol} / \mathrm{L}$ bortezomib for 24 hours. Thereafter, we examined cellular apoptosis by flow cytometry. Our data showed that the BMSCs reduced apoptosis of the myeloma cells and further inhibited bortezomib-induced apoptosis (Figure 1). To examine independent protective effects of soluble factors on the myeloma cells, we used $1 \mu \mathrm{m}$ transwell inserts to prevent physical contact of the myeloma cells with BMSCs but allowed soluble factors to pass freely through the membrane. The data showed no obvious protective effect of the BMSCs on the myeloma cells in the transwell inserts. Thus, these data indicated that direct adhesion can offer better protective effects against bortezomib-induced apoptosis than simple exposure to soluble cytokines (in transwell inserts).

\section{BMSCs activate NF-KB signaling pathway in myeloma cells}

We next determined whether the NF-KB signaling pathway was activated in the co-cultured system. We evaluated the expression of p-IKBa, p-P65 or P65 nuclear translocation in the myeloma cells after direct or indirect adhesion for 24 hours. Western blot results demonstrated that direct adhesion induced an increased expression of $\mathrm{p}-\mathrm{IKBa}$ and $\mathrm{p}-\mathrm{P} 65$. The expression level of P65 in the cytoplasm decreased while increasing in the nucleus (Figure 2). Moreover, the P65 differential changes in the cytoplasm and nucleus were not obvious in the transwell system. Similarly, the P65 nuclear translocation results were further validated by immunofluorescence assay (IFA). Taken together, our data showed that the activation of NF$\mathrm{KB}$ signaling pathway was involved in CAM-DR in myeloma cells.

\section{BMSCs up-regulate miR-30a-5p in myeloma cells}

We next determined whether the direct adhesion to BMSCs affect the expression of miRNA molecules in myeloma cells. We made miRNA chip analysis of U266, RPMI 8226 and H929 cells directly co-cultured with BMSCs for 24 hours. The data revealed a global miRNA expression profile in myeloma cells associated with CAM-DR (Figure 3). Further analysis showed that a miRNA-mRNA regulatory network existed in the myeloma cells, suggesting that the BMSCs promote survival and proliferation of the myeloma cells via the miRNA-mRNA network. We then evaluated six differentially expressed miRNAs by RT-PCR. Our data showed high expression of miR-30a-5p, miR-92b-3p, miR-125a-5p, miR-148a-3p, miR- 
200b-3p and miR-212-3p in U266, RPMI 8226 cells as well as primary myeloma cells after direct adhesion. On the contrary, there were no significant changes in the transwell system (Figure 3). Thus, these results demonstrated the involvement of miRNA molecules in regulating CAM-DR in the myeloma cells.

\section{NF-kB P65 directly binds to the miR-30a-5p promoter region}

Having demonstrated that the BMSCs could activate NF-KB signaling pathway and up-regulate the expression of miR-30a-5p, we speculated that there might be a correlation between NF-KB signaling pathway and the expression of miR-30a-5p. Our bioinformatics analysis suggested an existence of a transcription factor NF-KB binding site in the promoter region of miR-30a-5p (Figure 4B). We confirmed this prediction using chip analysis. The analysis showed that nuclear $\mathrm{P} 65$ bound to the miR-30a-5p promoter region (Figure 4A). These results demonstrated that BMSCs activated the NF-KB signaling pathway, followed by a distinct nuclear translocation of p65 and subsequent binding to the miR-30a-5p promoter region, which then triggered the miR-30a-5p transcription.

\section{BMSCs down-regulated BCL2L11 at both mRNA and protein level in myeloma cells}

BCL2L11 acts as an apoptotic activator that mediates multiple cellular activities. Here, we asked whether the BMSCs could regulate the expression of BCL2L11 in the myeloma cells. We interrogated shifts in the BCL2L11 mRNA or protein expression levels in myeloma cells directly or indirectly adherent to BMSCs. The RT-PCR results showed suppression of the BCL2L11 mRNA expression in directly adherent myeloma cells but not in the transwell system (Figure 5A). In addition, Western blot analysis showed that the BMSCs significantly reduced the BCL2L11 protein expression in myeloma cells that were in direct adhesion, but not in the transwell inserts (Figure 5B). Furthermore, the BMSCs decreased BCL2L11 mRNA and protein levels in myeloma cells induced by bortezomib. The above data demonstrated that the BCL2L11 was involved in protection of BMSCs against bortezomib induced myeloma cell apoptosis.

\section{BCL2L11 is a direct target of miR-30a-5p}

Our bioinformatics analysis suggested that the 3'-UTR of BCL2L11 contained a binding site that perfectly matched the seed region of miR-30a-5p (Figure 6A). We transfected the miR-30a-5p mimics or inhibitors into the myeloma cells with or without the BMSCs and examined the BCL2L11 protein expression. The data showed reduction of the miR-30a-5p mimics while the miR-30a-5p inhibitor increased BCL2L11 protein levels in U266 and RPMI 8226 cells (Figure 6C). Moreover, to confirm the direct interaction between miR-30a-5p and BCL2L11 gene, we constructed luciferase reporter genes which bore predicted miR-30a-5p binding site of the BCL2L11 3'-UTR or 3'-UTR mutant controls. The data showed that the miR30a-5p mimics successfully inhibited the luciferase activity in 293T cells transfected with wild-type BCL2L11 3'-UTR reporter constructs but not in the mutant controls (Figure 6B). These results demonstrated that the miR-30a-5p directly targeted BCL2L11 and promoted survival, proliferation and drug resistance in myeloma cells. 


\section{Overexpression of Bim or inhibition of miR-30a-5p expression reverse CAM-DR in myeloma cells}

Since BMSCs upregulated miR-30a-5p and downregulated BCL2L11, we determined whether the miR-30a$5 p$ downregulation or BCL2L11 upregulation could reverse CAM-DR in the myeloma cells. We first transfected miR-30a-5p mimics or miR-30a-5p inhibitor into the U266 or RPMI 8226 cells and then performed direct co-culture experiments. The results demonstrated that miR-30a-5p inhibition not only enhanced apoptosis and bortezomib sensitivity of myeloma cells but also partly abolished the CAM-DR phenotype (Figure 7C, D). On the contrary, miR-30a-5p mimics reduced cell apoptosis and increased resistance to bortezomib-induced cell apoptosis in the presence or absence of BMSCs (Figure 7A, B). We then examined the effects of BCL2L11 upregulation and BCL2L11 downregulation in the apoptosis of myeloma cells. As expected, overexpressed BCL2L11 displayed similar effects as miR-30a-5p inhibitor transfection, and ectopic inhibition of the expression of BCL2L11 conferred resistance to bortezomibinduced cell apoptosis with or without the BMSCs (Figure 7E, F, G, H). Taken together, these findings suggested that miR-30a-5p and BCL2L11 gene play crucial roles in the CAM-DR, and that the BMSCs induced a P65-miR-30a-5p-BCL2L11 amplification loop in the myeloma cells that promote cell survival, proliferation and drug resistance (Figure 8).

\section{Discussion}

Studies have showed dynamic interaction of myeloma cells with the surrounding tumor microenvironment in a mutually pro-survival fashion ${ }^{15-17}$. The tumor microenvironmental network promotes myeloma cell growth, survival, proliferation, drug resistance and angiogenesis by affecting various epigenetic and genetic molecular events, including miRNA alterations. Reagan et $a^{6}{ }^{6}$ identified dysregulated miRNAs in a three-dimensional co-culture system in vitro. The study reported that fifty-three miRNAs were obviously altered in mesenchymal stromal cells cocultured with MM1S cells. Notably, overexpression of miR-199a-5p promoted production of mineralized matrix and several common osteogenic gene expression, including alkaline phosphatase, collagen type I a1, integrin-binding sialoprotein, osteocalcin, osteopontin and runt-related transcription factor 2 . Morelli et al ${ }^{18}$ demonstrated that miR$125 b-5 p$ mimics weakened the protective effect of BMSCs, indicating a critical role of miR-125b-5p in the tumor micro-environment of the myeloma cells. In addition, another study showed an anti-tumor effect of miRNA in the tumor microenvironment, suggesting that overexpression of the miR-192 and miR-215 significantly reduced adhesion of the myeloma cells to $\mathrm{BMSCs}^{19}$. Other studies have shown that miRNAs could act as oncogenes in the tumor microenvironment. Maria et al ${ }^{20}$ showed that miR-21 expression was elevated in BMSCs adherent to myeloma cells and miR-21 inhibition in BMSCs resumed the physiological balance of RANKL/OPG. Another similar study revealed the carcinogenic role of miR-21 in the tumor microenvironment of myeloma cells, showing that miR-21 inhibitors impaired the survival fitness of myeloma cells provided by the surrounding environment ${ }^{21}$. As another oncomiRNA in the myeloma microenvironment, elevated miR-135b in MM-mesenchymal stem cells was associated with defective osteogenic differentiation, and miR-135b inhibitors effectively restored impaired osteogenic differentiation ${ }^{22}$. Consistent with our findings, Leotta et al. ${ }^{23}$ showed upregulation of miR-125a-5p in the 
myeloma cells adhered to BMSCs, and miR-125a-5p inhibitors suppressed growth and migration of the myeloma cells and induced cell apoptosis even in the presence of BMSC. Thus, miRNAs play pivotal roles in the tumor microenvironment. However, the underlying molecular mechanisms of myeloma cells adherent to BMSCs remain undefined. In this study, we showed dysregulation of miRNA-mRNA molecular network underlying CAM-DR of multiple myeloma. We demonstrated a key role played by upregulated miR-30a-5p in myeloma CAM-DR. However, the upregulation trend required direct cell-cell contact. Overexpression of the miR-30a-5p promoted the proliferation of myeloma cells and suppressed bortezomib-induced myeloma apoptosis in both suspension and co-culture status. Conversely, inhibition of miR-30a-5p increased bortezomib-induced myeloma cell apoptosis and partially abolished CAM-DR. Other studies also suggested a role of miR-30a-5p in the regulation of drug resistance. Li et al ${ }^{24}$ reported that miR-30a-5p was upregulated in cisplatin-resistant melanoma cells, and transfection of miR-30a-5p mimics in melanoma cells enhanced the cisplatin resistance, while inhibition of miR-30a-5p decreased the resistance of melanoma cells to cisplatin. Similarly, another study showed significant overexpression of miR-30a-5p in drugresistant ovarian cancer cells and the overexpression of miRNA-30a-5p promoted cell growth and colony forming ability, and enhanced cell migration and invasion ${ }^{25}$. Teng et $\mathrm{al}^{26}$ reported that serum miRNA-30a expression level was significantly higher in drug resistant nephrotic syndrome patients compared with drug sensitive patients. Taken together, miR-30a-5p acted as a communicator between myeloma cells and BMSCs, and more importantly, miR-30a-5p inhibitors might be potential clinical therapeutic tools in the management of CAM-DR in myeloma cells. Besides, studies have shown that BMSCs could activate various signaling pathways in myeloma cells, including NF-KB signaling pathway ${ }^{27}$. Here, we showed that BMSCs activate NF-KB in myeloma cells and then the nuclear RELA subunit directly binds to the miR-30a-5p promoter region, suggesting that inhibition of the NF-KB signaling pathway or miR-30a-5p might attenuate the supportive effect of BMSCs on the myeloma cells. In addition, BCL2L11 was demonstrated to play a regulatory role in the protective effect of BMSCs on the survival and proliferation of the myeloma cells ${ }^{28,29}$. In this study, we showed that both mRNA and protein expression levels of BCL2L11 decreased in the myeloma cells adherent to BMSCs. Moreover, restoring the BCL2L11 expression in MM-BMSCs increased myeloma cell apoptosis and partially reversed the CAM- DR phenotype. In addition, we demonstrated that BCL2L11 is a direct target of miR-30a-5p, suggesting potential therapeutic targets in CAM-DR myeloma cells.

Taken together, our study identified a tumor microenvironment mediated P65-miR-30a-5p-BCL2L11 amplification pathway in myeloma cells, providing new potential therapeutic strategies for clinical application and improving the prognosis of patients with myeloma.

\section{Declarations}

\section{Acknowledgements}

The authors received no financial support for the research, authorship, and/or publication of this article.

\section{Declaration of Conflicting Interests}


The authors declare that there is no conflict of interest.

\section{Statement of Ethics}

Written informed consent was obtained from all patients, and the study was approved by the Ethics Committee of the Affiliated Hospital of Nantong University (2012-005).

\section{Author Contributions}

Lingling Xie contributed to designing and drafting the manuscript. Xiuying Shi, Hongming Huang, Shaoqing Ju and Xudong Wang critically revised the manuscript. All the authors gave final approval of this article.

\section{References}

1. Ning J, Yang R, Wang H, Cui L. HMGB1 enhances chemotherapy resistance in multiple myeloma cells by activating the nuclear factor-kappaB pathway. Exp Ther Med. 2021;22(1):705.

2. Jin W, Wang X, Zeng Y, Lan Y, Wang X. Magnolol suppressed cell migration and invasion and induced cell apoptosis via inhibition of the NF-kappaB signaling pathway by upregulating microRNA-129 in multiple myeloma. Neoplasma. 2021;68(2):404-415.

3. Xie H, Gu Y, Wang W, Wang X, Ye X, Xin C, Lu M, Reddy BA, Shu P. Silencing of SENP2 in Multiple Myeloma Induces Bortezomib Resistance by Activating NF-kappaB Through the Modulation of IkappaBalpha Sumoylation. Sci Rep. 2020;10(1):766.

4. Wu Y, Zhu X, Shen R, Huang J, Xu X, He S. miR-182 contributes to cell adhesion-mediated drug resistance in multiple myeloma via targeting PDCD4. Pathol Res Pract. 2019;215(11):152603.

5. Allegra A, Ettari R, Innao V, Bitto A. Potential Role of microRNAs in inducing Drug Resistance in Patients with Multiple Myeloma. Cells. 2021;10(2).

6. Reagan MR, Mishima Y, Glavey SV, Zhang Y, Manier S, Lu ZN, Memarzadeh M, Zhang Y, Sacco A, Aljawai Y, Shi J, Tai YT, Ready JE, Kaplan DL, Roccaro AM, Ghobrial IM. Investigating osteogenic differentiation in multiple myeloma using a novel 3D bone marrow niche model. Blood. 2014;124(22):3250-3259.

7. Chen H, Cao W, Chen J, Liu D, Zhou L, Du F, Zhu F. miR-218 contributes to drug resistance in multiple myeloma via targeting LRRC28. J Cell Biochem. 2021;122(3-4):305-314.

8. Abdi J, Rastgoo N, Chen Y, Chen GA, Chang H. Ectopic expression of BIRC5-targeting miR-101-3p overcomes bone marrow stroma-mediated drug resistance in multiple myeloma cells. BMC Cancer. 2019;19(1):975.

9. Hao M, Zhang L, An G, Meng H, Han Y, Xie Z, Xu Y, Li C, Yu Z, Chang H, Qiu L. BMSCs protect myeloma cells from bortezomib induced apoptosis by suppressing microRNA-15a expression. Leuk Lymphoma. 2011;52(9):1787-1794. 
10. Wang X, Li C, Ju S, Wang Y, Wang H, Zhong R. Myeloma cell adhesion to BMSCs confers drug resistance by microRNA-21 up-regulation. Leuk Lymphoma. 2011;52(10):1991-1998.

11. Chen S, Zhang Y, Zhou L, Leng Y, Lin H, Kmieciak M, Pei XY, Jones R, Orlowski RZ, Dai Y, Grant S. A Bim-targeting strategy overcomes adaptive bortezomib resistance in myeloma through a novel link between autophagy and apoptosis. Blood. 2014;124(17):2687-2697.

12. Tsubaki M, Komai M, Itoh T, Imano M, Sakamoto K, Shimaoka H, Takeda T, Ogawa N, Mashimo K, Fujiwara D, Mukai J, Sakaguchi K, Satou T, Nishida S. By inhibiting Src, verapamil and dasatinib overcome multidrug resistance via increased expression of Bim and decreased expressions of MDR1 and survivin in human multidrug-resistant myeloma cells. Leuk Res. 2014;38(1):121-130.

13. Tsubaki $M$, Satou T, Itoh $T$, Imano $M$, Komai M, Nishinobo $M$, Yamashita $M$, Yanae $M$, Yamazoe $Y$, Nishida S. Overexpression of MDR1 and survivin, and decreased Bim expression mediate multidrugresistance in multiple myeloma cells. Leuk Res. 2012;36(10):1315-1322.

14. Zhang J, Yang X, Wang H, Zhao B, Wu X, Su L, Xie S, Wang Y, Li J, Liu J, Liu M, Han F, He T, Zhang W, Tao K, Hu D. PKCzeta as a promising therapeutic target for TNFalpha-induced inflammatory disorders in chronic cutaneous wounds. Int J Mol Med. 2017;40(5):1335-1346.

15. Garcia-Ortiz A, Rodriguez-Garcia Y, Encinas J, Maroto-Martin E, Castellano E, Teixido J, MartinezLopez J. The Role of Tumor Microenvironment in Multiple Myeloma Development and Progression. Cancers (Basel). 2021;13(2).

16. Giannakoulas N, Ntanasis-Stathopoulos I, Terpos E. The Role of Marrow Microenvironment in the Growth and Development of Malignant Plasma Cells in Multiple Myeloma. Int J Mol Sci. 2021;22(9).

17. Visram A, Dasari S, Anderson E, Kumar S, Kourelis TV. Relapsed multiple myeloma demonstrates distinct patterns of immune microenvironment and malignant cell-mediated immunosuppression. Blood Cancer J. 2021;11(3):45.

18. Morelli E, Leone E, Cantafio ME, Di Martino MT, Amodio N, Biamonte L, Gulla A, Foresta U, Pitari MR, Botta C, Rossi M, Neri A, Munshi NC, Anderson KC, Tagliaferri P, Tassone P. Selective targeting of IRF4 by synthetic microRNA-125b-5p mimics induces anti-multiple myeloma activity in vitro and in vivo. Leukemia. 2015;29(11):2173-2183.

19. Pichiorri F, Suh SS, Rocci A, De Luca L, Taccioli C, Santhanam R, Zhou W, Benson DM, Jr., Hofmainster C, Alder H, Garofalo M, Di Leva G, Volinia S, Lin HJ, Perrotti D, Kuehl M, Aqeilan RI, Palumbo A, Croce CM. Downregulation of p53-inducible microRNAs 192, 194, and 215 impairs the p53/MDM2 autoregulatory loop in multiple myeloma development. Cancer Cell. 2010;18(4):367-381.

20. Pitari MR, Rossi M, Amodio N, Botta C, Morelli E, Federico C, Gulla A, Caracciolo D, Di Martino MT, Arbitrio M, Giordano A, Tagliaferri P, Tassone P. Inhibition of miR-21 restores RANKL/OPG ratio in multiple myeloma-derived BMSCs and impairs the resorbing activity of mature osteoclasts. Oncotarget. 2015;6(29):27343-27358.

21. Leone E, Morelli E, Di Martino MT, Amodio N, Foresta U, Gulla A, Rossi M, Neri A, Giordano A, Munshi NC, Anderson KC, Tagliaferri P, Tassone P. Targeting miR-21 inhibits in vitro and in vivo multiple myeloma cell growth. Clin Cancer Res. 2013;19(8):2096-2106. 
22. Xu S, Cecilia Santini G, De Veirman K, Vande Broek I, Leleu X, De Becker A, Van Camp B, Vanderkerken K, Van Riet I. Upregulation of miR-135b is involved in the impaired osteogenic differentiation of mesenchymal stem cells derived from multiple myeloma patients. PLoS One. 2013;8(11):e79752.

23. Leotta M, Biamonte L, Raimondi L, Ronchetti D, Di Martino MT, Botta C, Leone E, Pitari MR, Neri A, Giordano A, Tagliaferri P, Tassone P, Amodio N. A p53-dependent tumor suppressor network is induced by selective miR-125a-5p inhibition in multiple myeloma cells. J Cell Physiol. 2014;229(12):2106-2116.

24. Li Y, Zhang J, Liu Y, Zhang B, Zhong F, Wang S, Fang Z. MiR-30a-5p confers cisplatin resistance by regulating IGF1R expression in melanoma cells. BMC Cancer. 2018;18(1):404.

25. Liu J, Wu X, Liu H, Liang Y, Gao X, Cai Z, Wang W, Zhang H. Expression of microRNA-30a-5p in drugresistant and drug-sensitive ovarian cancer cell lines. Oncol Lett. 2016;12(3):2065-2070.

26. Teng J, Sun F, Yu PF, Li JX, Yuan D, Chang J, Lin SH. Differential microRNA expression in the serum of patients with nephrotic syndrome and clinical correlation analysis. Int J Clin Exp Pathol. 2015;8(6):7282-7286.

27. Mekhloufi A, Kosta A, Stabile H, Molfetta R, Zingoni A, Soriani A, Cippitelli M, Paolini R, Gismondi A, Ricciardi MR, Petrucci MT, Masuelli L, Caracciolo G, Palchetti S, Santoni A, Fionda C. Bone Marrow Stromal Cell-Derived IL-8 Upregulates PVR Expression on Multiple Myeloma Cells via NF-kB Transcription Factor. Cancers (Basel). 2020;12(2).

28. Hazlehurst LA, Enkemann SA, Beam CA, Argilagos RF, Painter J, Shain KH, Saporta S, Boulware D, Moscinski L, Alsina M, Dalton WS. Genotypic and phenotypic comparisons of de novo and acquired melphalan resistance in an isogenic multiple myeloma cell line model. Cancer Res. 2003;63(22):7900-7906.

29. Tsubaki M, Takeda T, Yoshizumi M, Ueda E, Itoh T, Imano M, Satou T, Nishida S. RANK-RANKL interactions are involved in cell adhesion-mediated drug resistance in multiple myeloma cell lines. Tumour Biol. 2016;37(7):9099-9110.

\section{Figures}


A

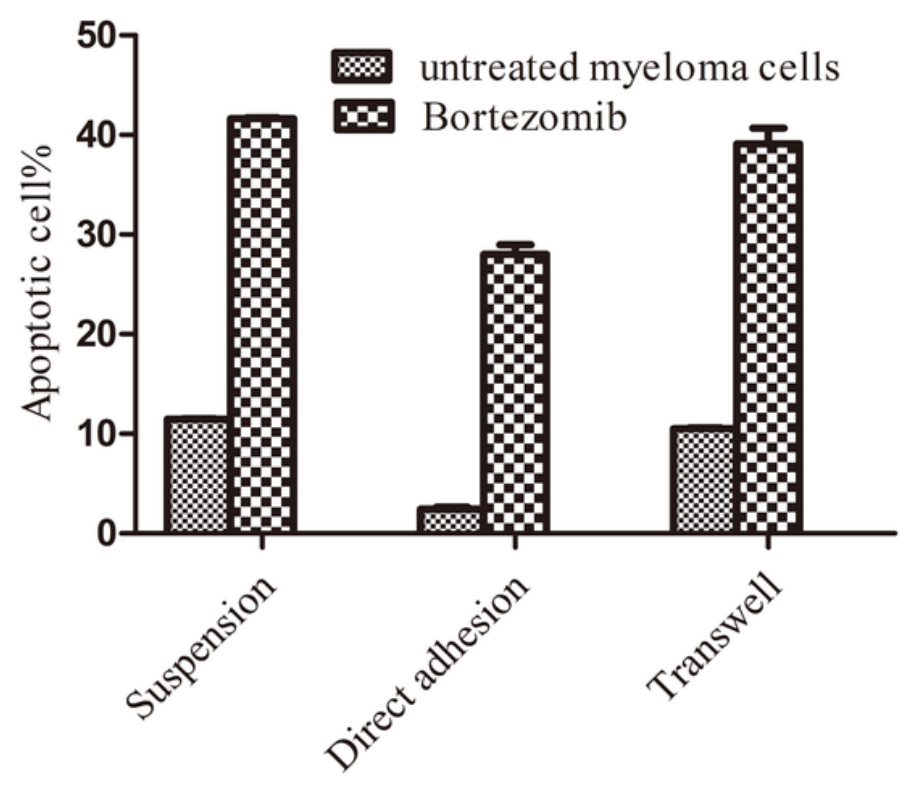

$\mathrm{B}$

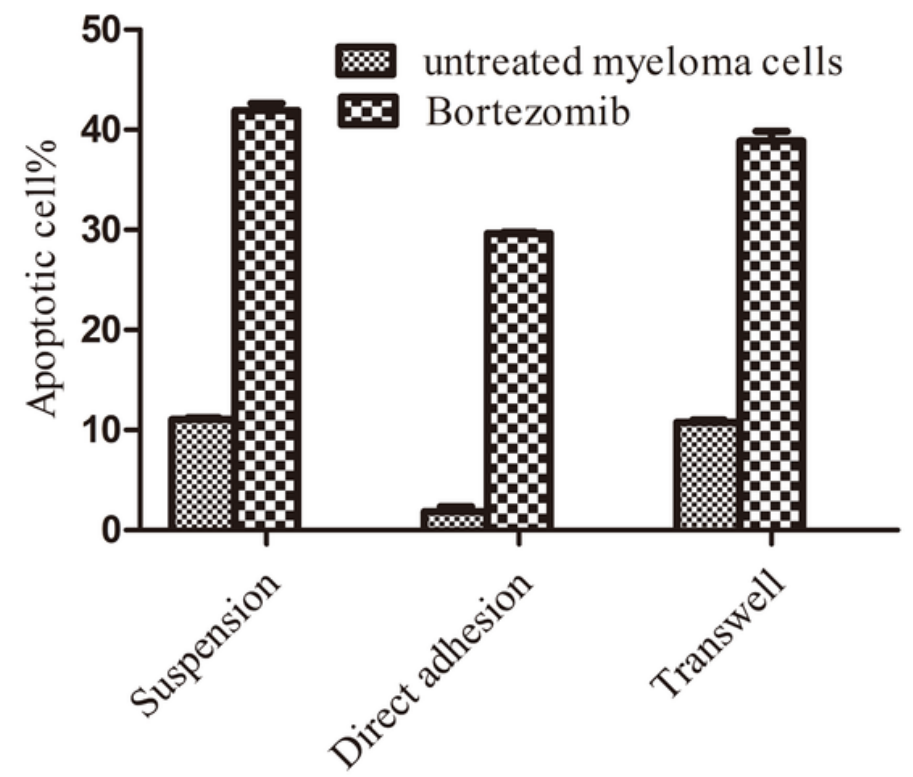

Figure 1

BMSCs protected myeloma cells from bort-induced apoptosis (U266 (A) and RPMI 8226 (B)cells in suspension directly adhered to BMSCs or separated by transwell inserts treated with $100 \mathrm{nmol} / \mathrm{L}$ bortezomib for 24 hours. Then the suspended myeloma cells were collected and cell apoptosis were analyzed by flow cytometry. The results represent three independent experiments with mean \pm SD). 

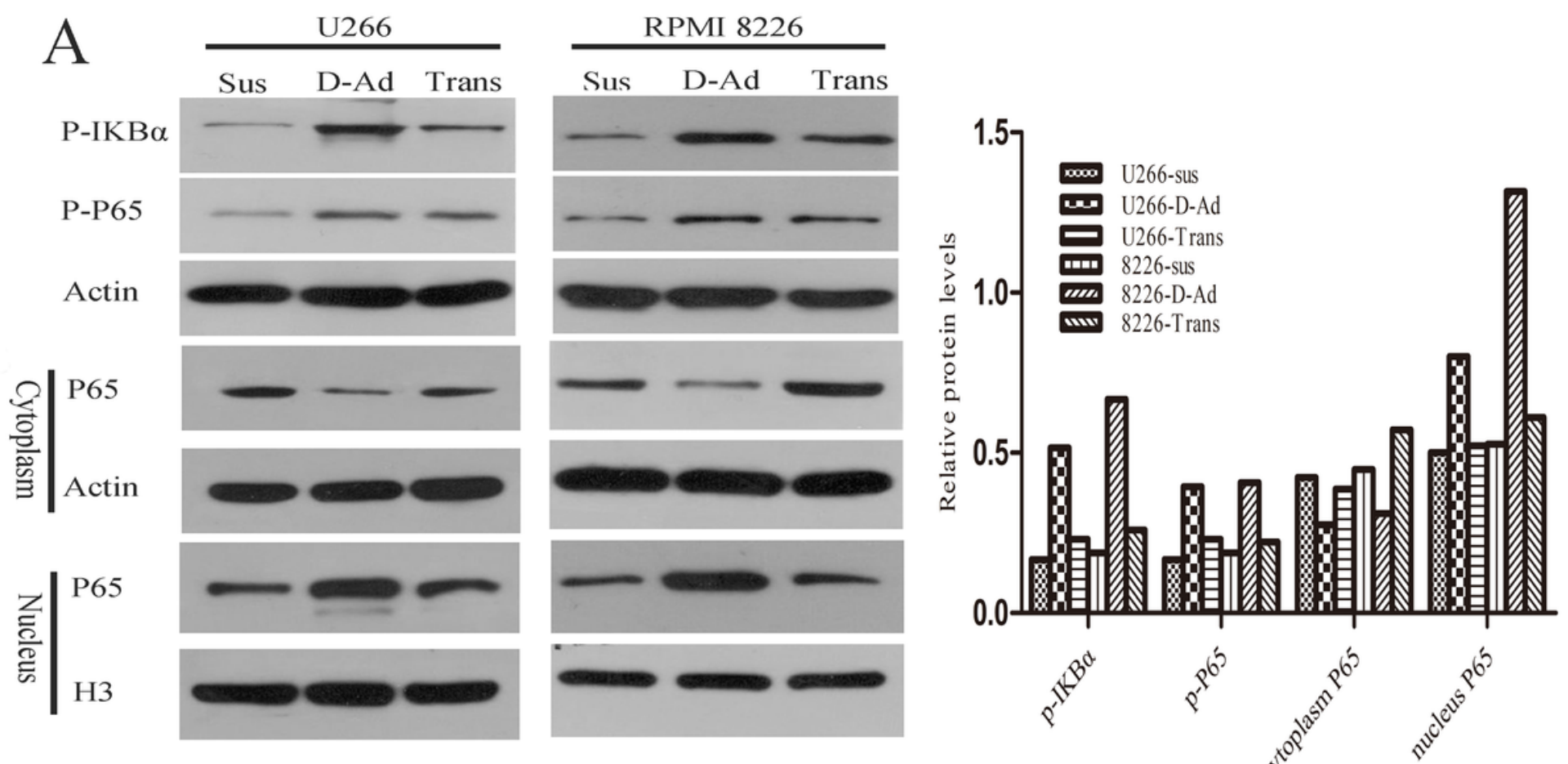

B

P65 Hoechst33342 Merge
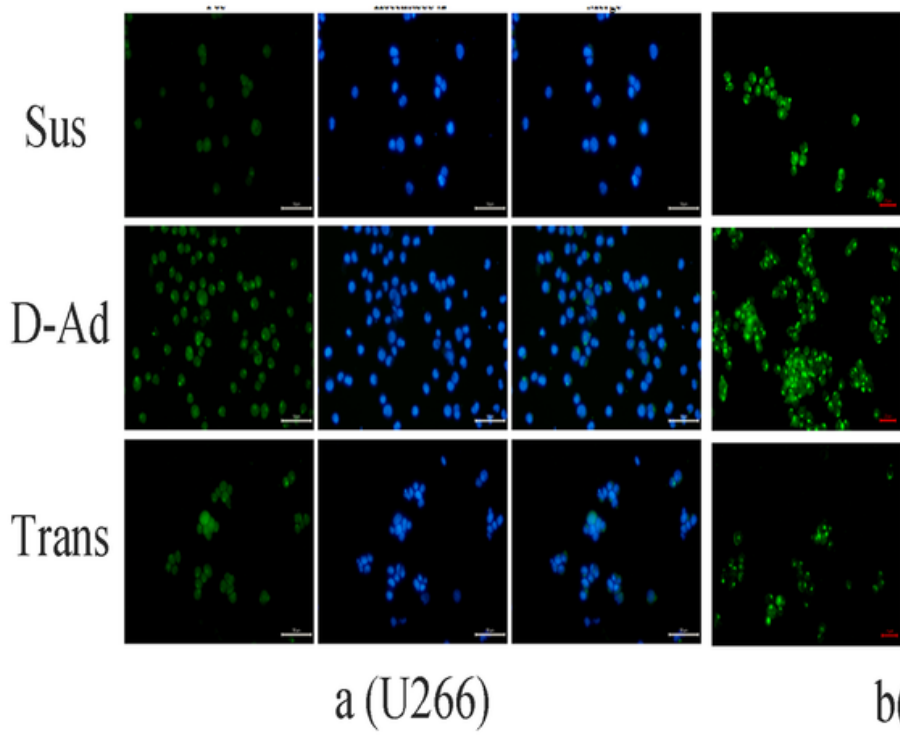

P65 Hoechst33342 Merge

P65 Hoechst33342 Merge
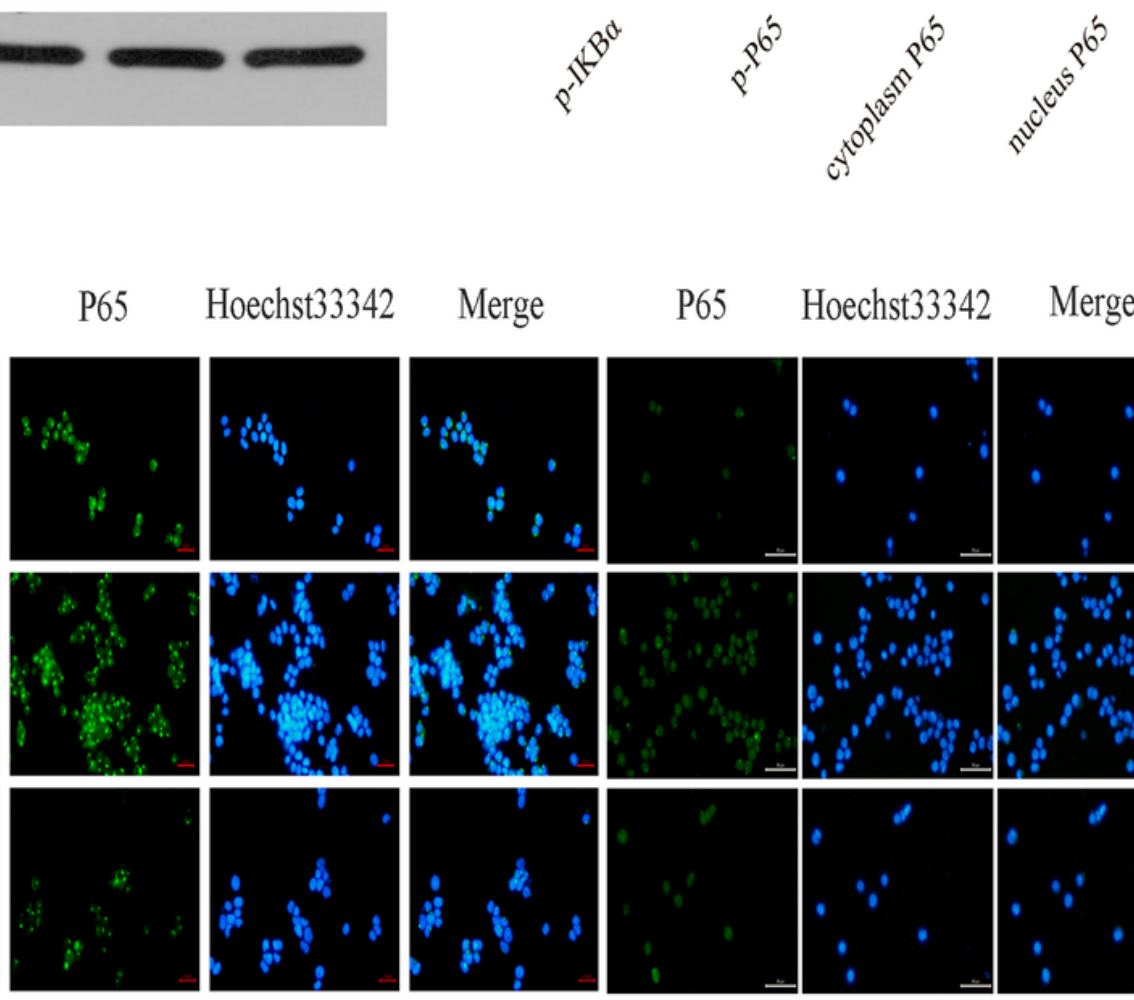

b(RPMI 8226)

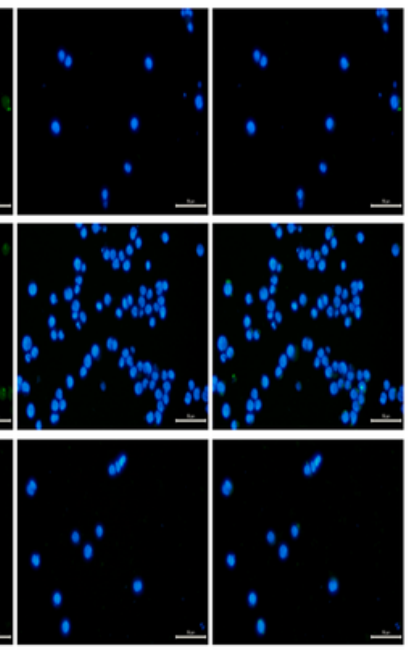

c(H929)

\section{Figure 2}

BMSCs activate NF-KB signaling pathway in myeloma cells (Myeloma cells co-cultured with BMSCs directly or in transwell inserts. p-IKBa, p-P65, P65 nuclear translocation was detected by western blot (A) or immunofluorescence assay (B). The relative change of BCL2L11 protein levels were measured by relative gray value and displayed under each lane $(A)$ ). 
A

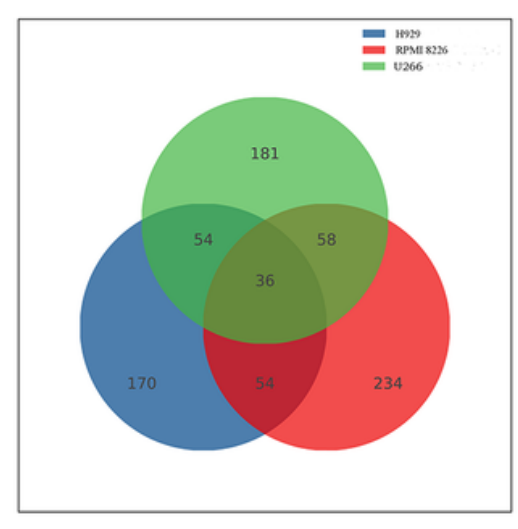

D
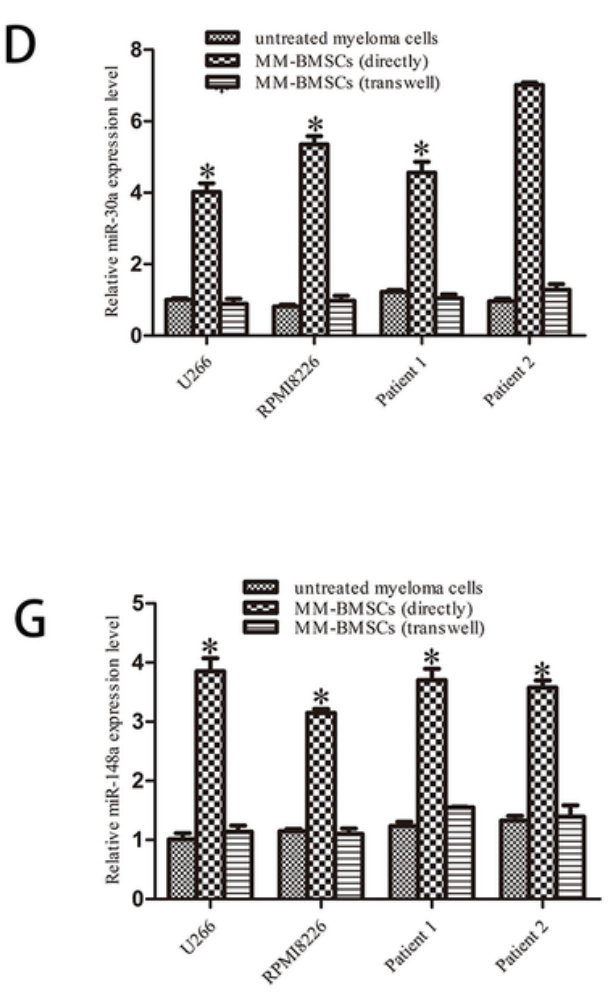
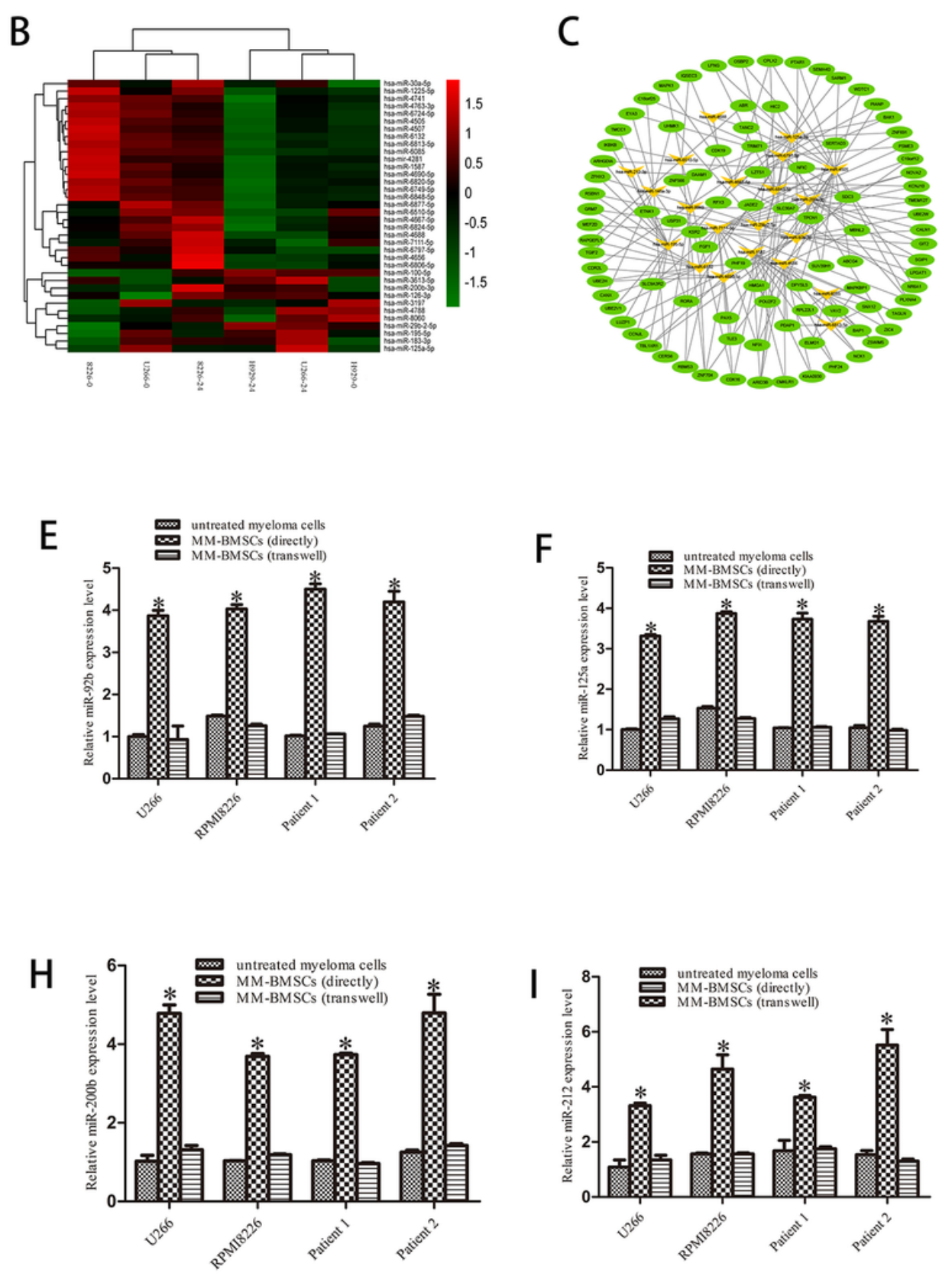

\section{Figure 3}

BMSCs regulated a miRNA-mRNA network in myeloma cells (We collected myeloma cells directly adhered to BMSCs for microarray assay and found a large number of dysregulated miRNA molecules(A). Common miRNA molecules differentially expressed in three myeloma cell lines screened by the chip (B) Bioinformatics tools predicted a miRNA-mRNA regulatory network in myeloma cells adherent to BMSCs(C). miR-30a-5p(D), miR-92b-3p(E), miR-125a-5p(F), miR-148a-3p(G), miR-200b-3p(H), miR-212- 
$3 p(I)$ expression were validated by RT-PCR and BMSCs obviously up-regulated miR-30a-5p in myeloma cells. $\left.{ }^{*} \mathrm{P}<0.05\right)$.

A

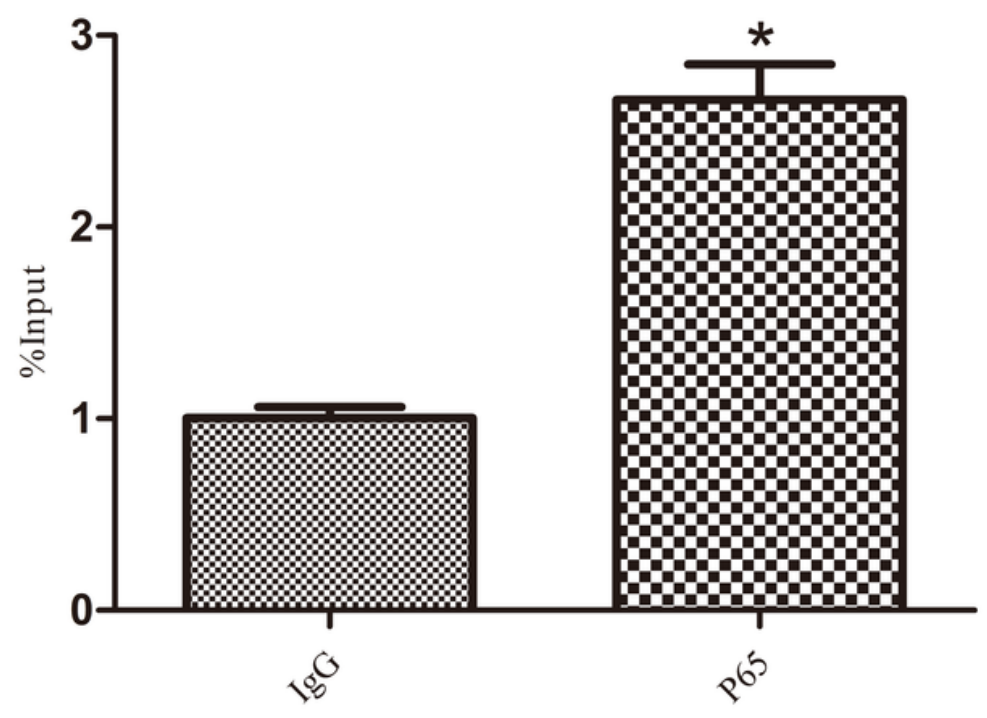

B

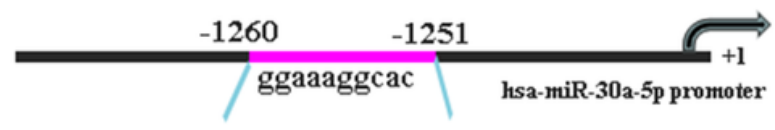

\section{Figure 4}

NF-kB p65 overexpression induced miR-30a-5p transcription (Bioinformatics tools predicted a binding site of NF-KB RELA and the promoter region of miR-30a-5p(B) chip analysis confirmed the direct binding of NF-KB p65 and miR-30a-5p promoter. $\left.{ }^{*} \mathrm{P}<0.05\right)$. 
A

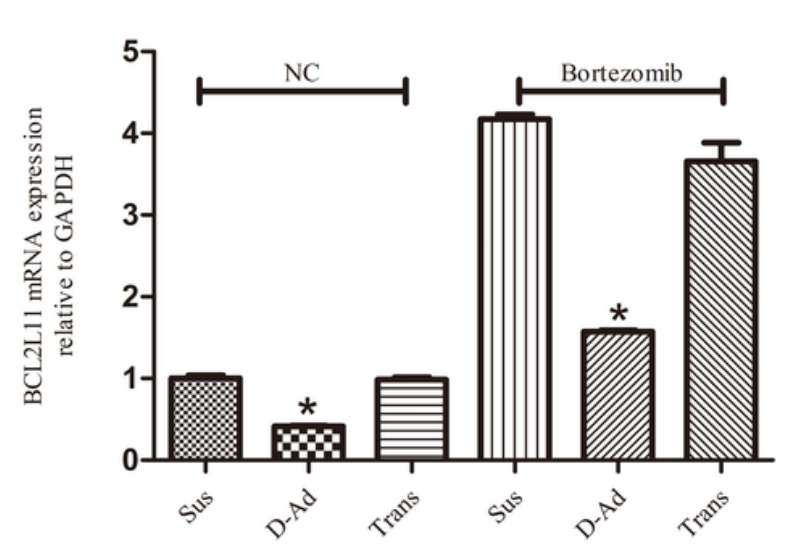

$\mathrm{B}$

BCL2L11
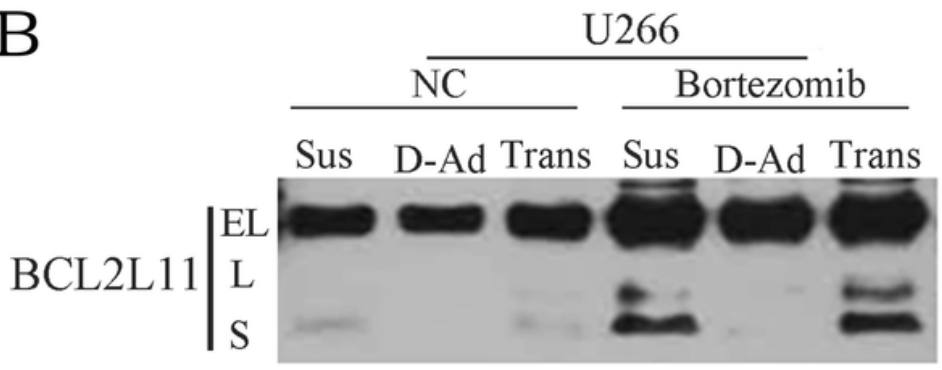

$\beta$-actin
C

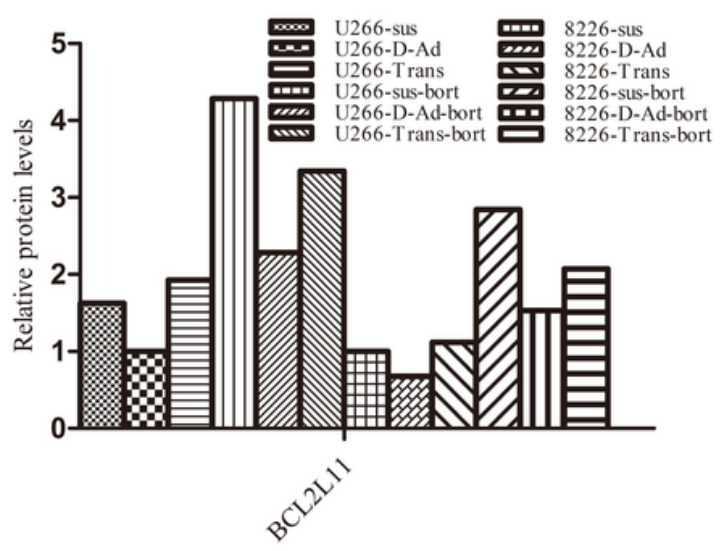

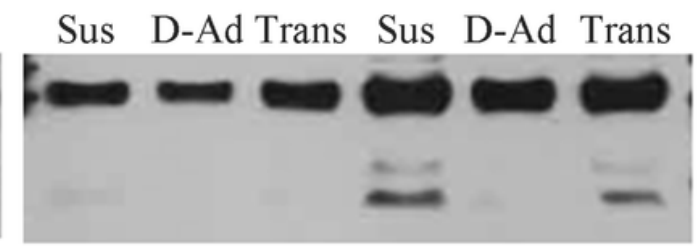

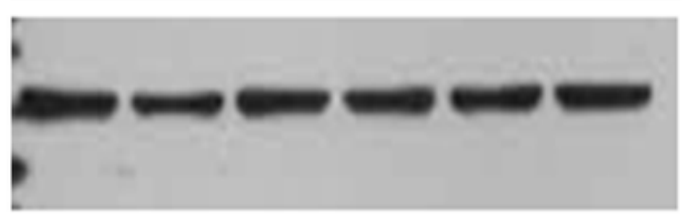

\section{Figure 5}

BCL2L11 was down-regulated both at the mRNA(A) and protein(B) level in myeloma cells cocultured with BMSCs (U266 and RPMI 8226 cells in suspension directly adhered to BMSCs or separated by transwell inserts treated with $100 \mathrm{nmol} / \mathrm{L}$ bortezomib for 24 hours. RT-PCR assay of BCL2L11 expression in different experimental groups $(A) * P<0.05$ Western blot analysis of BCL2L11 expression in each experimental groups(B)). 
poly A

A

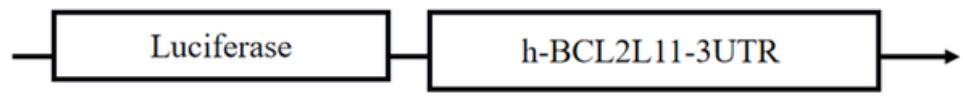

\author{
hsa-miR-30a-5p \\ h-BCL2L11-3UTR-wt \\ h-BCL2L11-3UTR-mu
}

3'....GAAGGUCAGCUCCUACAAAUGU...5'
||||||||
5'....UUGUGUAAGAAUGGUGUUUACAU... 3'
5'....UUGUGUAAGAAUGGAGAUGAGAU... 3'

B

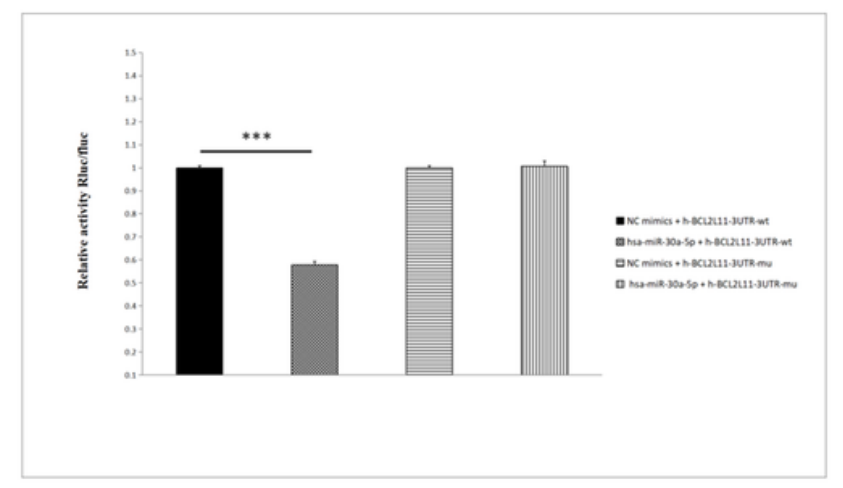

C

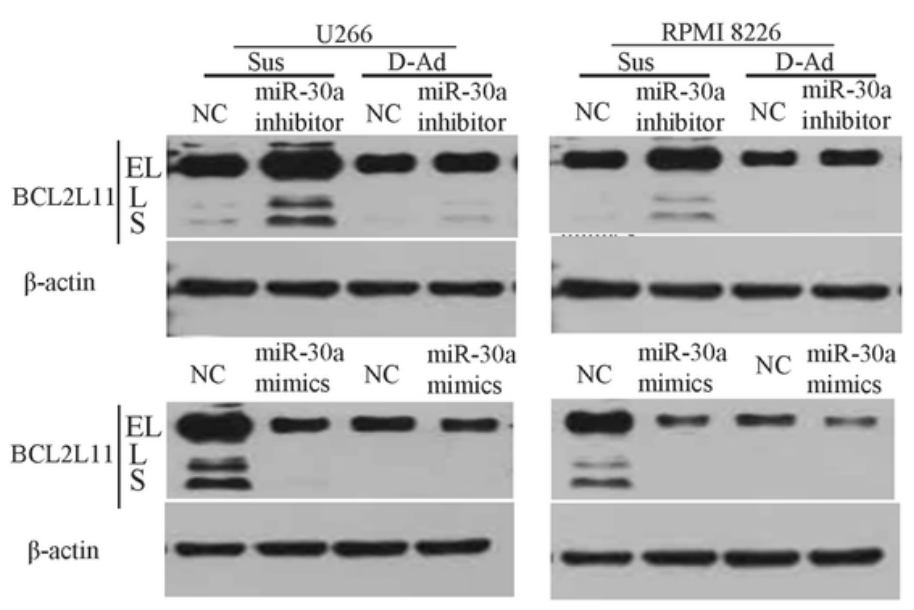

\title{
Figure 6
}

BCL2L11 was the direct target of miR-30a-5p (Bioinformatics tools predicted a binding site of miR-30a-5p in the 3'-UTR region of BCL2L11 gene(A) HEK293T cells were transfected with miR-30a-5p mimics, wildtype and mutant BCL2L11 3'-UTRs, Renilla luciferase results confirmed BCL2L11 as the direct miR-30a-5p target gene(B) ***Pख0.001 U266 and RPMI 8226 cells in suspension directly adhered to BMSCs or separated by transwell inserts were transfected with miR-30a-5p mimics and inhibitor, western blot analysis of BCL2L11 expression in different experimental groups(C)) 
A

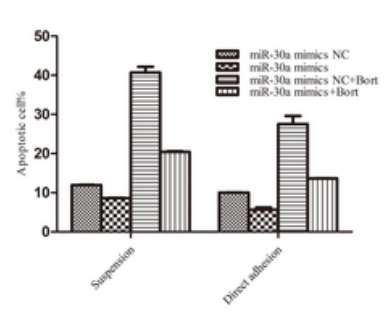

B

$\mathrm{E}$

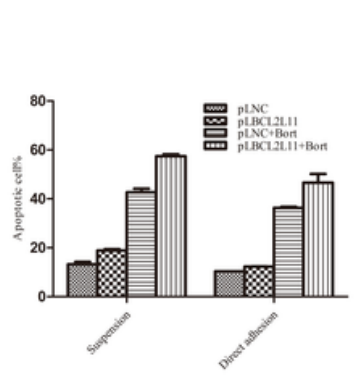

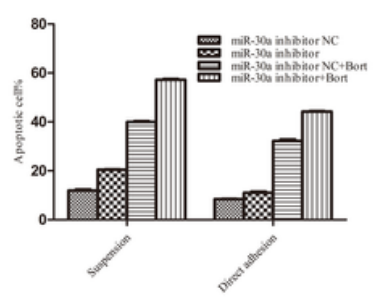

$\mathrm{C}$

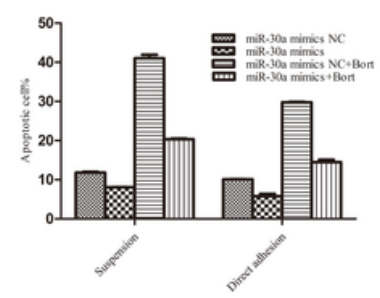

G

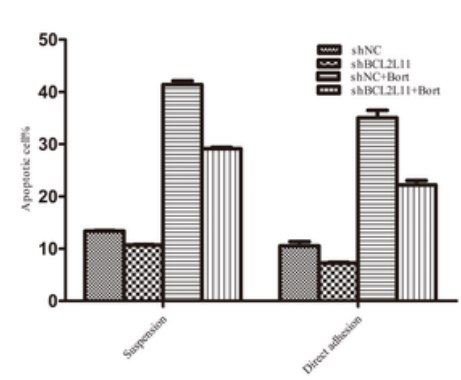

$\mathrm{D}$

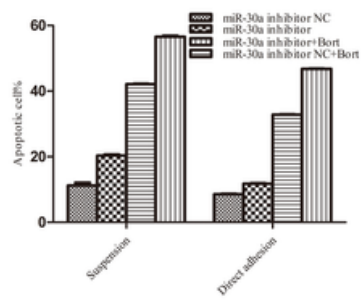

$\mathrm{H}$

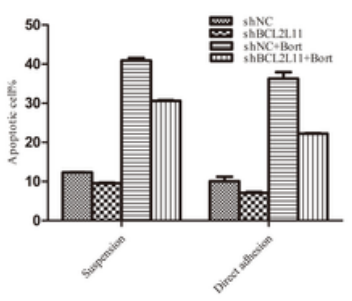

Figure 7

Inhibition of miR-30a-5p or overexpression of BCL2L11 conquered CAM-DR (U266 and RPMI 8226 cells in suspension or directly adhered to BMSCs were transfected with miR-30a-5p mimics, miR-30a-5p inhibitor (A, B, C, D) plBCL2L11 plasmid and shBCL2L11 plasmid $(E, F, G, H)$, cell apoptosis was analyzed by flow cytometry based on annexin V/PI staining in each group. Datas collected from three independent experiments. 


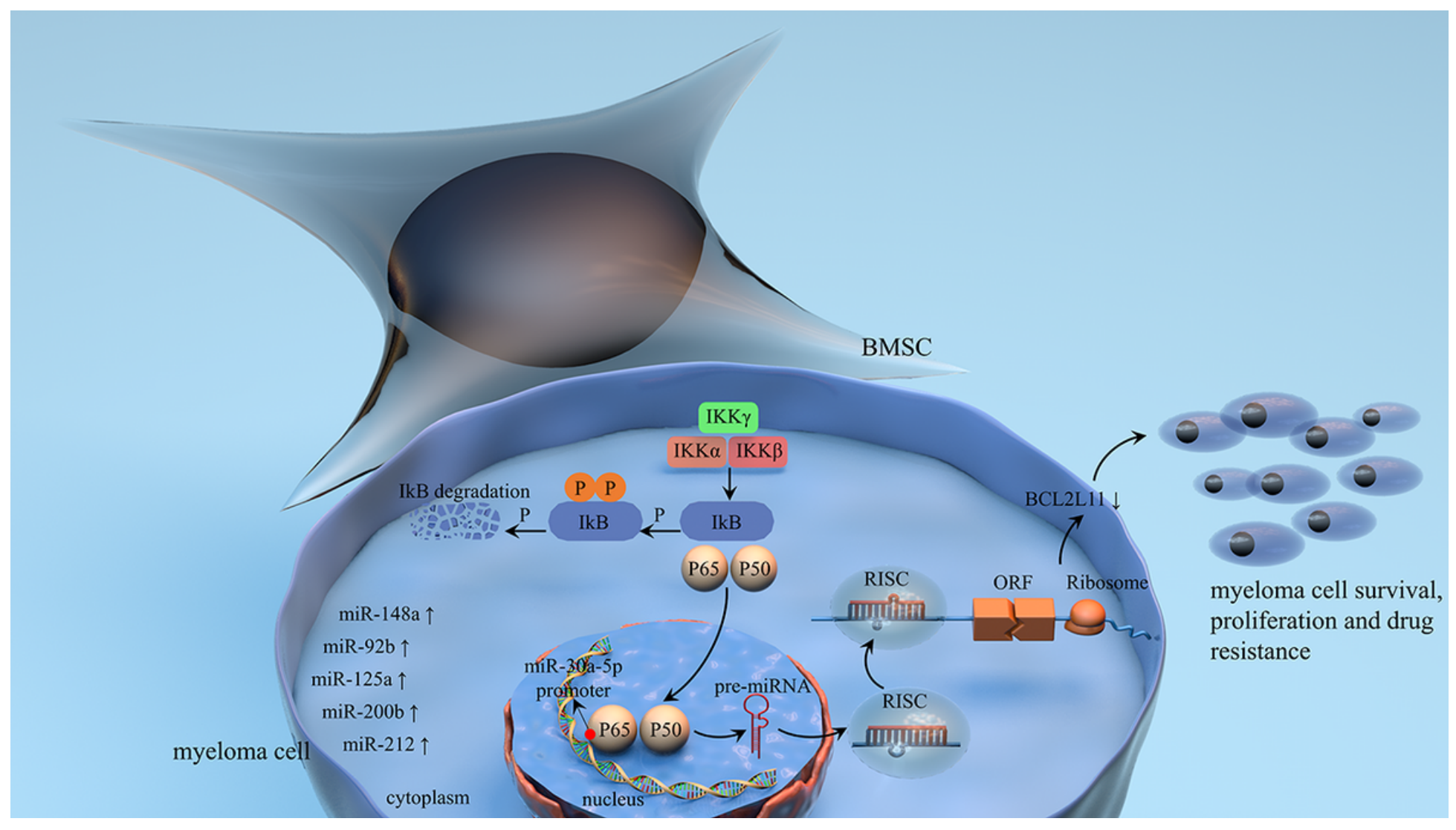

\section{Figure 8}

Summary of the mechanisms of miRNAs, including miR-30a-5p of CAM-DR in myeloma cells 